\title{
THE ROLES AND RESPONSIBILITIES OF ACTION RESEARCH NETWORKS IN TIMES OF CRISIS: LESSONS FROM THE ACTION RESEARCH NETWORK OF THE AMERICAS
}

\author{
Meagan Call-Cummings \\ George Mason University \\ Melissa Hauber-Özer \\ George Mason University \\ Lonnie Rowell \\ Social Publishers Foundation \\ Karen Ross \\ University of Massachusetts
}

\begin{abstract}
Against the backdrop of the COVID-19 pandemic, we explore the perceived roles of action research networks during times of crisis and then consider our own experiences grappling with our responsibilities as members of the Action Research Network of the Americas (ARNA) in highlighting and building solidarity through its Knowledge Democracy Initiative and Social Solidarity Project. To critically reflect on our work, we consider the usefulness of Gaventa's (1991) three strategies for knowledge democratization to action research networks in "perilous" times and the responsibility of action research scholars-advocates-activistsparticipants to anchor our work in an ethos of knowledge democracy. In conclusion, we issue a call to embrace critical, participatory forms of action research, and creative, new pathways for the work of knowledge democracy.
\end{abstract}

KeY WoRds: Action research; Knowledge democracy; Solidarity; Responsibility; Crisis; COVID-19; Pandemic 


\section{INTRODUCTION}

On the surface, action research and action research networks would seem to be wellpositioned to address crises. The combination of being grounded in community-practices in relation to in-the-trenches issues of disadvantage, oppression, marginalization, and empowerment and having the capacity to efficiently launch studies and projects based on this grounding provides a significant advantage for action researchers and scholar-activists engaged with crises in their own communities (Kemmis, McTaggart, \& Nixon, 2014). Yet, in the face of the current pandemic, there is scant evidence to date that action research has played much of a role in grassroots responses to the pandemic. We have chosen to examine the potential of action research networks to pivot towards a more activist orientation in responding to a global crisis such as the current pandemic and to use our direct involvement with one of those networks (i.e. the Action Research Network of the Americas, or ARNA) as a case-study of the opportunities and challenges.

Three action research networks developed between the mid-1970s and the mid-1980s to foster knowledge creation and exchange, particularly in the discipline of education: the Collaborative Action Research Network (CARN), based in the UK, the Action Learning and Action Research Association (ALARA), based in Australia, and Participatory Research in Asia (PRIA), based in India (Riel, 2017). The early 2000s saw the emergence of additional networks, including the Nordic Network for Action Research (NNAR), the international Pedagogy, Education, and Praxis (PEP) network, the Canadian Association of Action Research (CAARE-ACRAÉ), and the Action Research Network of the Americas (ARNA) (Riel, 2017). Each network has distinctive values, practices, and areas of focus, typically grounded in the contexts and concerns of members. For example, NNAR emphasizes Nordic educational traditions of lifelong learning (bildung), popular adult education (folk enlightenment), and relational, collaborative, and dialogical pedagogy as routes to social justice and human development (Rönnerman et al., 2016). PEP, on the other hand, primarily seeks to respond to the global, twenty-first century push for standardization and accountability measures in education by supporting action research and critical praxis at the local level (Edwards-Groves \& Kemmis, 2016).

These networks have become increasingly formalized, establishing paid memberships, organizing annual conferences, study days, and workshops, and publishing peer-reviewed scholarly journals (e.g. CARN's Educational Action Research Journal) as well as newsletters and conference proceedings to disseminate action research from around the globe (Balogh, McAteer, \& Hanley, 2017; Riel, 2017). Regional and national subnetworks have also sprung up within the networks: for example, CARN now has groups in, among other places, Norway and Greece, and has German- and Spanish-speaking networks (Balogh et al., 2017). In addition, the larger networks frequently collaborate, as when ARNA co-organized a major international conference in Cartagena, Colombia with CARN, ALARA, PEP and others in 2017, and when CARN and ALARA held a combined annual meeting in Split, Croatia in 2019.

These and other AR networks have been organized in an effort to enable the flow of social capital and knowledge through relations built on trust and respect (Riel, 2017), and to "promote action research that is conducted with a commitment to honesty, integrity, 
inclusiveness, multi-vocality, engagement, and achievement within sustainable democratic societies" (Action Research Network of the Americas [ARNA], 2020, "Mission"). Given AR's resistance toward "the mainstream positivist paradigm" (Zuber-Skerritt \& Passfield, 2017, p. 419), and the critical epistemology underlying participatory approaches (Call-Cummings \& Hauber-Özer, 2018; Freire, 1970; Gaventa, 1991), these networks have also served an important purpose in providing infrastructure and moral support to those engaging in this type of inquiry (Zuber-Skerritt \& Passfield, 2017, p. 419).

In our review of the websites, mission documents, and selected publications of these AR networks and their members, we have noticed that, while all of them share goals of promoting AR, they do not share one single definition of AR, nor do they seem to promote a common approach to action-oriented research. Given the extraordinary times in which are living, when evidence is rejected in favor of power (Nichols, 2017), truth is skewed and contorted depending on interest (McIntyre, 2018), and justice is applied only when convenient, it is the purpose of this manuscript to advocate for an approach to AR that is explicitly anchored in an ethos of knowledge democracy, which calls for a breaking of the knowledge monopoly held by those in positions of power and a recognition of the value of the multiple ways of knowing of those who are marginalized and excluded; "knowledge democracy is about intentionally linking values of democracy and action to the process of using knowledge" (Hall \& Tandon, n.d., "Knowledge democracy").

We ask, what is the role of AR networks in knowledge democratization, in producing and disseminating the people's knowledge, in times of crisis? We examine this question in the context of one, small AR project intended to build global solidarity during the COVID-19 pandemic. We begin by offering a brief background on the pandemic and its relation to the work of one AR network, the Action Research Network of the Americas (ARNA). We then turn to our own experiences grappling with what our roles should be as members of ARNA as we attempted to both highlight acts of and build solidarity during the pandemic through our Social Solidarity Project (SSP) and its more inclusive Knowledge Democracy Initiative. We conclude with a discussion on the responsibility of AR scholars-advocates-activistsparticipants to return to the roots of critical, participatory forms of action research, to repoliticize the work we do, and to creatively open up pathways for other action researchers to grow into and own their roles as scholar-activists resisting the neoliberal project.

\section{Covid-19 PANDEMIC}

During the winter of 2019, all eyes were on China, and then on Italy at the outset of 2020, as the COVID-19 pandemic spread like wildfire. Those of us outside of those countries and without friends or family members there watched the news and followed our Twitter feeds, awestruck, disbelieving. We saw death counts and infection rates skyrocket. Those of us with family members and friends in those places heard personal stories of healthcare workers on shift for days on end, and magnanimous taxi drivers transporting those workers to and from their shifts. We read about food and supply shortages through social media. As educators, we received direct pleas urging us to practice extraordinary empathy for students unable to come back to classes in the United States or simply unable to focus because of personal stresses. 
And then the first cases were identified closer to home. The news felt more real and more likely to touch us. We began to stock up on essentials and searched for masks on the internet, unable to find suppliers. When school districts closed one after the other, we tried to figure out ways to creatively homeschool our children and let many of our professional commitments go for the foreseeable future. And we 'social distanced', a new concept in March 2020 that now, as we write three months later, seems normal. We stayed away from everyone except our immediate family members. No contact. No touching. Six feet away.

Many of us in academia began to receive emails about special funding from foundations and other sources to conduct research related to the pandemic. Some seemed in bad taste, capitalizing on the fears, struggles, and pain so many were experiencing. Others made more sense to us. As we vented about our own frustrations and worries, we encouraged each other to find ways to feel - and be - helpful. As researchers who most often engage in action-oriented forms of inquiry and who are committed to doing research with communities rather than on them, we knew it was not only a goal, but a responsibility, to contribute positively and productively in the moment. But how?

\section{A KNOWLEDge Democracy STRATEgy for AR NetWorks in Times of CRisis}

We turned to John Gaventa (1991), who offers three primary strategies, formulated for adoption in the North American context, that can be used by AR networks as they engage in knowledge democratization in times of crisis like these: reappropriation of knowledge, developing the people's knowledge, and popular participation in the social production of knowledge. Reappropriation of knowledge refers to people gaining power over knowledge about their lives and communities. As Gaventa notes, in the 'knowledge society' of North America, there is abundant information, but it typically remains monopolized by the elite and by knowledge specialists, out of reach for those it affects (Gaventa, 1991). The participatory movement demands public access to such information, which Gaventa (1991) asserts is empowering in that it enables people to "investigate reality for themselves" (p. 125), view themselves as researchers, and develop "other popular and indigenous ways of gaining information from the power structure" (p. 125).

The second and interdependent strategy, developing the people's knowledge, highlights the value of "folklore, popular knowledge, or popular wisdom" that is typically excluded from the "formal scientific structure built by the intellectual minority of the dominant system" (Gaventa, 1991, p. 127, citing Fals-Borda, 1982). This strategy is revolutionary "because it involves a breach of the rules, and hence its subversive potential" (Gaventa, 1991, p. 127, citing Fals-Borda, 1982). Gaventa asserts that this kind of knowledge production naturally leads to action:

Seeing themselves capable of producing and defining their own reality they may actively seek to change it, a greater consciousness and analysis of the political context and of their situation may develop and the new knowledge becomes a resource for challenging the hegemony of the dominant ideas. (p. 129)

In other words, knowledge is power. 
Gaventa's (1991) third strategy, popular participation in the social production of knowledge, is based in the understanding that not everyone needs to become an expert. Gaventa maintains that there are different "forms of democratic participation and control in defining the problems to be studied, in setting research priorities and in determining how the results are to be used" (Gaventa, 1991, p. 129). These models, however, "demand new forms of accountability" (Gaventa, 1991, p. 130); "fundamental questions must be raised about what knowledge is produced, by whom, for whose interests and toward what end" (p. 130).

\section{ARNA, THE KNOWLEDGe Democracy InItiative, AND the Social Solidarity Project}

ARNA was established in 2012 and has since grown into a "social and intellectual space within which new initiatives could be launched, new collegial relationships could be established, and alternative forms of knowledge production and knowledge dissemination could be practiced" (Rowell, Bruce, Shosh, \& Riel, 2017, p. 492). In the fall of 2019, Meagan Call-Cummings emailed Lonnie Rowell, one of ARNA's founders, to volunteer to help galvanize efforts around the ARNA's Knowledge Democracy Initiative, which aims to "position ARNA as a global leader in exploring democratized knowledge production as a basis for public discourse and public policy and as a core contributor to shaping a $21^{\text {st }}$ century progressive political agenda that is inclusive and humanistic". Together, we identified others within our own networks to join a team that would set out on this mission. We worked by email, phone, and virtual meetings and grew confident in our abilities to complete the tasks in meaningful ways within the time we had allotted.

And then the world changed. While attempting to strengthen ARNA's work on knowledge democracy, we were suddenly in the thick of a pandemic, which deeply impacted our thinking on how to move forward. More than anything, we began to feel isolated in ways we had never felt before. Unable to connect with each other or others in ways we were used to because of the pandemic's requirement of social distancing, we began to feel as many around the world felt - isolated, alone, fearful, hungering for connection. That is when the Social Solidarity Project (SSP) was born.

Before describing the SSP, it is necessary to make clear who we are in relation to it and to the world. Meagan Call-Cummings, a white, female, middle class, junior faculty member at a public university, is contributing to this manuscript in her new 'office' in the garage of her townhome, in the suburbs of Washington, DC, USA. Her space heater is keeping her relatively comfortable but her focus drifts in and out because of her young children peeping their heads in and out of her 'office' asking questions about what they should eat for lunch, if they can watch television, or when she will be done with work. She is deeply aware of her privilege, but unsure how to disentangle herself from it, questioning what is needed right now.

Melissa Hauber-Özer, a white, female, doctoral candidate from a working-class family, is writing from her home office in southeastern Turkey, where she relocated a few years earlier due to her Turkish spouse's job as a university faculty member and her dissertation research about Syrian refugees. Her interest in AR had grown out of her years teaching 
English as a second language and literacy to adults in the US, where many of her learners faced intersecting forms of marginalization. This led to her working as Call-Cummings' graduate research assistant during her doctoral program and to increasing involvement in CARN and ARNA. As an immigrant far from home and with limited ties to her local community, the project has been a source of encouragement and a reminder of the moment's universal human experiences she is sharing in.

Lonnie Rowell, a white male retired faculty member living in New Mexico, has been involved with AR for three decades. A baby boomer who grew up in a US Navy family, he came into adulthood in the turbulent 1960 s and was profoundly changed by the experience. The activism that seeped into the core of his being at this time has never left. He views American history through a critical lens, and believes the overlapping privileges of race, class, and gender that he has enjoyed are a call to pay back and pay forward for what has come easier to him in life while simultaneously and systematically being denied to others. His belief that the recognition of someone else's oppression represents a challenge to his own capacity for empathy, compassion and action has kept him determined as a learner and an activist for the many decades of his adulthood. As a co-founder of ARNA and as the current coordinator of the ARNA Knowledge Democracy Initiative, he recognizes both the difficult challenges associated with knowledge democratization in a time of global crisis and the many opportunities to demonstrate the potentials of AR to contribute to greater social justice.

Karen Ross, a white, Jewish-Israeli-American female junior faculty member at a public university, writes from the one room in her house in central Massachusetts where it is (sometimes) possible to focus without interruption from the two children to whom she has become educator and support specialist as well as mother. As a peacebuilding practitioner, Ross has long been involved with initiatives that seek to reframe and dismantle dominant narratives, especially as they serve oppressive functions - initiatives that have shaped her academic work and her engagement with AR. At the same time, she is cautious about her role in speaking as someone from a place of privilege and dominance (in both countries she calls home). Ross' involvement with the SSP is borne from her commitment to the democratization of knowledge, and, simultaneously, from her trepidation about perpetuating inequities that have been so deeply ingrained and exacerbated in the current context.

Prior to moving into her new garage office, and in the context of crushing and constant media reports of COVID-19 death statistics and social distancing requirements, CallCummings suggested to others in ARNA, including Hauber-Özer, Rowell, and Ross, that they engage the network in a Social Solidarity Project (SSP) with the twin goals of both highlighting simple acts of solidarity around the world and building solidarity, especially among those most directly affected by the global pandemic. She envisioned the project as a form of photovoice activism, inviting submissions of original photographs and short descriptions in any language depicting social solidarity.

Working quickly, our team put together a call for participation. Yet, in the midst of our seemingly constant email exchanges, doubts emerged. It became apparent that we would 
necessarily be excluding many of the most vulnerable in this pandemic. What about those who are migrants, living in camps that are already struggling with crowded conditions, poor sanitation facilities, and lack of access to medical care and material resources? What about those caught in judicial/prison systems who do not have the ability to physically distance and who often survive emotionally on visits from loved ones but could no longer have that? What about those who were dying alone, who could not be surrounded by their parents, children, or other caregivers? Would it even be possible to reach these people? To build solidarity with them? To honor their experiences? Would this project be meaningful without them?

In response to our concerns, we outlined four priorities and added them to the web-based version of the call:

1. Recognizing and expressing solidarity with healthcare, homecare, daycare and all other 'essential' workers (e.g. grocery stores, gas stations, etc.);

2. Critiquing/examining/exposing issues of social isolation and marginalization in relation to refugees and immigrants being contained;

3. Expressing concern for people in jails, prisons and other involuntary institutionalization settings, and at the same time, critiquing/examining/exposing issues of invisibility and dehumanization in relation to inmates and the institutionalized in general;

4. Expressing social solidarity with patients as they deal with recovery from COVID-19.

We also drew on our own linguistic resources and those of our networks to translate the call into French, German, Spanish, Portuguese, Mandarin, Cantonese, Turkish, and Arabic in hopes of expanding access to participation. These translations were added to the project webpage and shared through our social and professional networks. Hauber-Özer has been the primary point of contact for the SSP, monitoring the email account and posting submissions to ARNA's Knowledge Democracy Initiative website.

Here, we aim to provide a useful analysis of our experiences with our network's response to the COVID-19 pandemic. Within Gaventa's (1991) discussion of three strategies discussed earlier, he includes a call for action researchers and, we would argue, action research networks, to consider "fundamental questions...about what knowledge is produced, by whom, for whose interests and toward what end." This emphasis on basic questions about what and whose knowledge counts has guided our thinking as we reflect on how our team has anchored our efforts in an ethos of knowledge democracy.

\section{THE FUNDAMENTALS}

This return to the fundamentals is simultaneously self-critique and celebration. We understand that there is always much to be learned from imperfect efforts. While we reflect on the ways in which ARNA's Knowledge Democracy Initiative may move forward, we celebrate what we have achieved in highlighting acts of solidarity across the globe, especially in places and contexts so often forgotten, deemed uninteresting or politically unimportant, and especially in seemingly simple ways. We also celebrate how the SSP has begun to build solidarity through the project. By sharing these photographs and stories, we 
have strengthened and grown our network while, hopefully, illustrating ARNA's priority of engaging in knowledge democratization in meaningful ways.

\section{What Knowledge is Produced ANd By Whom?}

In considering what knowledge has been produced through the Social Solidarity Project, and in the context of the knowledge democratization responsibilities of an AR network, we consider a fundamental, epistemological anchor of AR to be: expertise lies with those who are closest to an issue, problem, or phenomenon. This idea is inextricably linked to the concept and practice of knowledge democracy, turning more traditional approaches to research and knowledge production on their heads, flipping the script of who knows, whose knowledge is valuable, and who decides which knowledges are worth including or amplifying. More traditional (positivist) approaches to research both explicitly and implicitly claim that those who are privileged with material wealth, status, or formal education are the experts in particular fields or disciplines. Critical, participatory forms of action research argue that while these people may very well hold knowledge in certain areas, they do not own that knowledge, nor do they get to determine whose knowledge is useful or to delineate where valuable knowledge stops and starts.

Because the SSP has been necessarily web-based, it has been tricky to maintain our stance on this epistemological ground. We all believe and aim to live up to this and to practice reflexivity about how we can more authentically democratize knowledge. Indeed, we began the SSP with the main goal of highlighting acts of solidarity to better understand how solidarity is manifested in various contexts around the world, what solidarity means in various spaces, and what acts of solidarity are meaningful to people in various positions and circumstances. Our goal was to:

...[speak] back against and [tear] down this ideology of fear and separation and [move] individuals, communities, and nations toward a recognition of the social solidarity that is both necessary and already occurring every day in public and private spaces around the world. (SSP Call for Participation Draft, March 21, 2020)

We endeavored to open up space for ordinary people across the world to both highlight and express solidarity with those directly affected by the pandemic. And yet, we wonder who has been positioned as the expert and gatekeeper through the project? For example, it is clearly an ARNA project, which is dominated by white institutional researchers, with men in the most prominent positions. While this is not an indictment of those men or ARNA, it is simply a fact. While the demographics of ARNA leadership and membership are changing to include many more women and people of color, it is difficult to escape the current reality.

Who are the gatekeepers? As readers of this manuscript may notice, we all identify as white academics who live or were raised in the United States and who are privileged in terms of material wealth and educational - as well as employment - status. While we hope addressing this issue explicitly will to some extent alleviate some discomfort, the facts are plain: we are the gatekeepers for this project. If a submission arrives in our project email inbox that seems out of place or in other ways 'inappropriate' to include in the Social Solidarity Gallery, we are the ones who decide what gets posted and what does not. What 
does this signify about whose knowledge is produced? Who becomes the 'owner' of this knowledge?

Related to these questions, we wonder whose voices are actually being included in the SSP and what barriers are perpetuating the, perhaps unintended, exclusion of knowledges even in this attempt? Especially early on in the project, we questioned the dearth of submissions sent in. Perhaps we had visions of going 'viral,' but even three weeks after sending the call for participation to all our own professional, academic, and personal networks, we only had a handful of submissions, a few of which, we admit, were our own!

We agreed that perhaps people were either inundated with similar requests or were overwhelmed with the pressures of daily living during a pandemic that we were also facing. University faculty members - including much of the ARNA network - were scrambling to move face-to-face courses online with little training or support, many while juggling childcare and remote schooling. Worldwide, we were seeing skyrocketing levels of anxiety and isolation and reading that the global crisis was provoking symptoms of traumatic stress. We, too, were struggling with difficulty concentrating and sleeping, with mounting fears about our loved ones in essential jobs and in high-risk categories, and with worries about the future of our jobs and our children's education. In short, we were living in crisis mode.

In addition, some people we invited, scholars and practitioners both in the Global North and Global South, seemed concerned or even afraid of the overt political nature of our call and the project itself, and therefore chose not to contribute. This politicization of showing solidarity has become a central question we ponder in our work. In a sense, we see this as limiting democratization of knowledge because those most at risk from speaking up are those least likely to feel they can contribute.

As we pondered these twin realities of potential participants being inundated with requests for participation in similar projects and being concerned about how our expressions of solidarity could be construed, still convinced that our simple project had the potential to offer comfort and encouragement, we wondered how we could garner more participation. Hauber-Özer sent an email to Call-Cummings and the research team suggesting that perhaps we needed to take a different tack, one that was more firmly anchored in democratized approaches:

I suspect that if we simplify the request without the kind of academic explanation (a picture and a few sentences showing social solidarity/human connection during the pandemic) and reach out to, for example, Facebook groups where people are sharing this kind of thing already, we could potentially gather a bunch more submissions. When it sounds like a bigger/more serious request, people might hesitate to submit...I shared mainly with my more academic networks initially because I thought that's who'd be interested, but I realized that isn't really democratizing knowledge. There are expat groups, for example, where people are sharing photos of neighbors delivering groceries; my school's Whatsapp groups for teachers are filled with photos of students making rainbow signs, etc. Basically, this 
is happening already but not being gathered in a researchy way. Does that make sense? Should we try to shift our approach a bit? [Try] to get outside the silo of academia and gather the people's knowledge... (personal communication, April 22, 2020)

Rowell responded:

I think your analysis is spot on in terms of both the proliferation of web-based supports and the noticeable intensification of distress being experienced as we all settle in with the realization of what a mess this is and how long we all will be dealing with it...Globally, we may have entered a zone that is way beyond 'compassion fatigue' and makes it harder for people to feel like sharing expressions of solidarity. Although I have to say that my communications with friends in the UK indicate that solidarity is very much appreciated on a daily basis, and my viewing of CNN, MSNBC, local news, etc. shows me it is alive and well here as well, even in the face of the multiple expressions of craziness in [the United States]. So, I see the relevance of what we are doing, although I also see the need to adapt and adjust as things unfold. (personal communication, April 24, 2020)

Agreeing to adapt and shift our approach, members of the SSP team sent an updated, shortened, and less 'researchy' invitation to friends, family members, and other acquaintances. While perhaps not a direct, causal connection, we did notice a subsequent uptick in submissions.

When a handful of submissions came in that did not conform to our project parameters of a photograph and short description, we decided to adjust again. We added a second project subpage to the website, titled "Social Solidarity News and Initiatives" to display submissions containing links to online events, blogs, social media pages, and fundraising or awareness-raising efforts. In this way, we sought to honor the people's knowledge and use our platform - limited though it may be - to highlight social solidarity movements that aligned with our purpose.

In considering this example of how the SSP team learned to exercise our commitments in simple ways, we reflect on Margaret Riel's (2017) words, cited earlier in this manuscript. She suggests that one of the ways we can overcome barriers to participation in action research is to work to develop and maintain an equitable and consistent flow of social capital and knowledge through relationships built on trust and respect. By letting go of academic jargon and expanding our view to potential participants in our everyday lives, we leveraged existing, trusting, respectful relationships and also ended up building new ones. For example, SSP has garnered over half of its submissions from people in Sri Lanka because of one trusted, respected network member. At the same time, we have built a new relationship with a professor in Canada who is originally from Nepal and engages in advocacy efforts both among the Nepali community in her city and back home.

Finally, we reflect on who does the labor, both for the SSP and in other action research network projects. In considering how we have operated the SSP, we have noted that most 
of the day-to-day labor has been done by the group's lowest-ranking member, HauberÖzer. Call-Cummings asked Hauber-Özer, as her graduate research assistant, to provide support that she (Call-Cummings) could not give due to new demands on her time (homeschooling young and adolescent children). While, again, these reasons seem perfectly 'normal' and justifiable, we cannot help but wonder about the critical implications of this. It is worth exploring whether this is just a coincidence or a pattern in AR networks. Along with reflexivity around the knowledge that is produced, candid examinations of the distribution of labor in such projects would be a valuable addition in realigning our work with Gaventa's (1991) strategies.

\section{FOR WHOSE INTERESTS AND TOWARD WHAT END?}

This fundamental question is, of course, intricately connected to the questions we have posed in the preceding section and to our responsibility as action researchers to intentionally anchor our work in both the ethos and practices of knowledge democracy. They are also deeply interwoven with our own positionalities. Ultimately, we have to consider who benefits most from this effort. We stand to reap both tangible and intangible benefits: potential publications and presentations to add to our CVs, particularly important for Call-Cummings, Hauber-Özer, and Ross, as early career scholars, as well as the satisfaction of conducting meaningful research during a global crisis and the morale boost of reading the submissions. That said, the large number of submissions from Sri Lanka, including many in the Sinhalese language and several from classroom teachers, and expressions of thanks for the opportunity to write in their own language indicates that the project offered - and continues to offer - a valuable platform for expression. Perhaps this in itself is enough to consider the project a success in democratizing knowledge.

While it is hard to know so early in the project's life how this knowledge is being used, it seems to us that in producing material for the SSP, people who contribute are taking control of the narratives they want to disseminate about what is happening in their homes, lives, and communities - likewise in the initiatives discussed on the website. Instead of being told how the pandemic is decimating their (or other) communities, the posts are illustrating both what people are doing for others and what they are drawing on for their own sustenance. In a sense, the posts are flipping the narrative about the pandemic. The project has been successful at subtly but meaningfully addressing the politicization of solidarity by taking back creation, 'ownership,' and dissemination of the narrative(s). In this small but significant way, then, we believe that the project has provided a forum for reappropriating and developing the people's knowledge, Gaventa's (1991) first two strategies.

We have documented experiences and perspectives that likely would not appear in 'traditional' research, revealing several fascinating trends. Predictably, technology featured in a number of submissions from various locations as a means to continue education and to communicate with loved ones. Creative arts, including drawing, making jewelry, creating collages, and playing musical instruments, appeared to offer solace for many. Contributors in the Western hemisphere tended to focus on acts of solidarity: making and donating face masks, displaying hearts, rainbows, or teddy bears in windows to support essential workers, and collecting and distributing food aid to struggling families. Submissions also 
revealed a fascinating theme of solidarity with and through the natural world. Many of our Sri Lankan contributors, in particular, described gardens, plants, and wildlife - both literally and metaphorically - as sources of comfort and sustenance. Though not represented in the project gallery, we have also noticed a return to traditional activities among our networks: friends are baking bread for the first time, learning to knit, and planting gardens, seemingly taking refuge from a chaotic, uncertain world in simple, lifesustaining tasks. These themes might necessitate a reconsideration of the dominant focus in much action research on formal education and an increased consideration of the value of informal learning and the natural world.

In addition, we have seen contributors redefining participation for themselves in terms of the different kinds of submissions they have contributed: images, blog posts, and initiatives. Some participants have submitted their own reflections on solidarity and what it means. Some have submitted information about other kinds of solidarity being expressed, thus deciding for themselves what should be considered expressions of solidarity. And so on. This echoes the epistemological commitments that anchor critical, participatory forms of action research and underscores Gaventa's (1991) third strategy, popular participation in the social production of knowledge. By insisting on expanding the definition of solidarity and highlighting forms and acts of solidarity that may not have otherwise been considered, the Social Solidarity Project has illustrated that there are different "forms of democratic participation" that are valuable in "defining the problems to be studied, in setting research priorities and in determining how the results are to be used" (Gaventa, 1991, p. 129).

At the same time, we need to reflect on whose voices are not represented and how our approach may have neglected to account for technological divides or remained too firmly ensconced in academic networks. We should consider how we can live out our commitment to knowledge democracy and incorporate more accountability in our work as individual scholars and ARNA members going forward.

Finally, we must both recognize (and perhaps to a certain extent, accept) and devise meaningful ways to push back against the neoliberal establishment which holds the economic power to dominate the social constructions of culture, and do so in a way that rejects the 'anti-science' and 'post-truth' environment we are living in, while critically resisting the force of scientism. In the current context, this means, among other things, that mass media expressions of such things as 'care,' 'community,' and even 'solidarity' are overwhelmingly defined by a corporatized view that legitimizes a single, dominant narrative at the expense of all others. A little project like ours is extremely hard put to compete with the high-end technology and production values of, say, a commercial portraying a chain restaurant's definition of 'caring' during the pandemic. In other words, our submissions cannot match mainstream visual, musical, and voice-over expressions of care or solidarity, even when we are confident our values are more closely aligned with the grassroots concerns of those in the margins. This dilemma is reinforced by the overwhelming emphasis during this crisis on knowledge produced in the medical sphere, relying on "objective," dispassionate accounts. A project such as ours that amplifies 
alternative modes of knowledge production, and that can raise questions about dominant narratives, inevitably faces challenges.

\section{DiscuSSION AND REFLECTION}

In the preceding sections of this manuscript we attempted to address the 'small step' that SSP represents in relation to the whole of the COVID-19 pandemic and AR networks' responsibility to center our work intentionally and explicitly on the ground of knowledge democracy. We may ask ourselves, is such a project 'the best' that our network can do in relation to the need for democratized knowledge and the roles of action research networks? What else might we have done (and could do for that matter)? We see other examples of how other AR networks have responded to the pandemic and compare our efforts. For example, PRIA Youth, based in New Delhi, organized a webinar titled, "COVID19 and Young People: Impact and Solutions" (PRIA Youth Team, 2020). Here, it can be noted that as a 'first generation' AR network, PRIA has far more resources than ARNA, a much longer history, and a much more active network. Perhaps our reason for launching the SSP was that we were all feeling the call for 'isolation' as an afront to our inclinations to connect. Whatever the case, our effort may seem miniscule in retrospect compared with what we envision AR networks could and should be doing in relation to knowledge democracy, whether or not a global crisis is happening.

Yet, in reflecting on Gaventa's (1991) three strategies for knowledge democratization we would argue that no matter the scale, no matter the perceived 'impact,' as AR networks, we must scrutinize our practices, even the minute details, to assure we are constantly trying to live up to our own commitments to knowledge democratization. This is an aspiration, yes, but one that requires ongoing work and reflexivity. Reflecting on these 'fundamental' questions may be a starting point, but we must dig deeper and do the difficult work of shifting reality and the way things presumably have to be, drawing on renewed understandings of what it is to work on changing the policies that tell us what needs to be. Indeed, this is the work of action research. This discussion re-engages Gaventa's (1991) three strategies to begin that process of 'digging deeper.'

\section{REAPPROPRIATING KNOWLEDGE}

As a reminder, Gaventa (1991) uses this idea of reappropriating knowledge in the context of North America because of the monopolization of information by those who are in positions of power. This knowledge monopoly, Gaventa argues, holds relevant and useful knowledge back from those who are affected by it, thereby committing violence against those individuals and communities. Similarly, Jordan and Kapoor (2016) assert that AR "has been increasingly appropriated by the neoliberal project" (p. 135) and demand that we reclaim and re-politicize it "as a methodology of and for the margins" (p. 140-141). This return to the roots of critical, participatory forms of action research, which are antihegemonic, anti-capitalist, and anti-colonial, would stand in stark "opposition to neoliberal ideology, policy and practice" (p. 136). Therefore, our first suggestion related to the roles and responsibilities of action research networks is that action research networks must actively and transparently push back against neoliberal appropriation of knowledge and knowledge production processes in every aspect of our work, not just in the organized projects in which we engage. We recognize the enormous challenges of trying to 'compete' 
with the culture-making machine of the powers that be. Through this project, we have come to better understand the need for even more imaginative efforts to construct creative solutions in times of global crisis, including the current pandemic.

\section{Developing the People's KNoWledge}

According to Gaventa (1991), his second knowledge democratization strategy rests on valuing what he calls popular knowledge. That is, the knowledge that is under- or devalued by dominant systems and structures. The SSP offers a clear example of how this can be achieved even on a very small-scale during times of global crisis. When the whole world seems to be caught in a never-ending cycle of believing and disbelieving media related to the pandemic, the SSP offered an opportunity for ordinary people to offer up their own realities based in their own expertise. As people, we are experts on our own lives, our own communities, our own realities. The SSP showed that that expertise matters and is valuable. By creating a space for that expertise to be shared and recognized, the SSP fulfilled a core responsibility of action research networks: creating space for the people's knowledge to be honored, valued, and shared.

\section{Popular Participation in the Social Production of Knowledge}

Gaventa's (1991) third strategy is tied up with his second, yet there are unique aspects to how this was accomplished through the SSP and how action researchers may see their responsibilities and roles moving forward. Gaventa argues that "obviously the only response to expert domination is not to clone the expert in every person, or even in every oppressed group" (p. 129). In many action-oriented research projects we have seen university-based researchers attempt to 'train' individuals and communities in the methods that university-based researchers know and see as valid. While we acknowledge that this can be one useful approach depending on one's goals, we would argue that what Gaventa suggests is something that SSP strove for: a valuing of everyday, or ordinary, inquiry methods. In these days where it seems everyone has a smart phone, social media is power. The SSP asked people to do what they were already doing - to document their everyday lives in the midst of a global pandemic and then to share it with the rest of the world on this platform. The body of knowledge that was produced was surely vastly different than what would have been produced through methods university-based researchers may have used. We could have attempted to use a validated survey instrument or other tool. Yet, by emphasizing and connecting the social nature of knowledge, knowledge production, and people's power, the SSP shone a light on experiences that may not have otherwise been acknowledged. No matter the possibility for shortcomings - and we have exposed many - action research networks must take on the responsibility to democratize even the very methods we use, and the SSP was one example of that.

\section{Conclusion}

The current pandemic serves as a reminder of the fragility of our institutions and systems, the vulnerability many of our fellow humans face, and the importance of connection and kindness in sustaining individuals and societies. As academics committed to democratizing knowledge, we must account for these truths and work towards a more humanizing pedagogy and research (Spooner \& McNinch, 2018). At the same time, we must forge on in this work of building and growing AR networks that take on the call to democratic 
knowledge creation and practice and evidence-based peacebuilding, even in the midst of global crises. The work will not - ever - be perfect. We both accept that and push ourselves to remain constantly vigilant in our imperfect efforts.

This Social Solidarity Project offers one example of moving forward with knowledge democratization in the context of a global crisis. It serves as a possibility for creating space for the people's knowledge while also exposing many limitations of the work. It is a heartfelt and appropriate response by an action research network to living during a pandemic and it builds on the potential of critical, participatory action research to 'make a difference' in relation to difficult social problems. This goal, we believe, should guide the efforts of AR networks during times of crisis.

\section{REFERENCES}

ARNA. (2020). About. Retrieved from https://arnawebsite.org/about/

Call-Cummings, M., \& Hauber-Özer, M. (2018). The potential of (participatory) action research for school leaders, local policy makers, and university-based researchers. In C. Lochmiller (Ed.), Complementary research methods for educational leadership and policy studies (pp. 121-140). Palgrave Macmillan, Cham.

Balogh, R., McAteer, M., \& Hanley, U. (2017). Maintaining a network of critical connections over time and space: The case of CARN, the Collaborative Action Research Network. In L. L. Rowell, C. D. Bruce, J. M. Shosh, \& M. M. Riel, The Palgrave international handbook of action research (pp. 403-418). Cham: Palgrave Macmillan.

Edwards-Groves, C., \& Kemmis, S. (2016). Pedagogy, education and praxis: Understanding new forms of intersubjectivity through action research and practice theory. Educational Action Research, 24(1), 77-96. https://doi.org/10.1080 /09650792.2015.1076730

Fals-Borda, O. (1982). Participatory research and rural social change. Journal of Rural CoOperation, X(1), 25-40.

Freire, P. (1970). Pedagogy of the oppressed. New York, NY: Herder and Herder.

Gaventa, J. (1991). Toward a knowledge democracy: Viewpoints on participatory research in North America. In O. Fals-Borda \& M. A. Rahman (Eds.), Action and knowledge: Breaking the monopoly with participatory action-research (pp. 121-131). New York, NY: Apex Press.

Hall, B. \& Tandon, R. (n.d.). Are we killing knowledge systems? Knowledge, democracy and transformation. Retrieved July 1, 2020, from http://www.politicsof evidence.ca/349/ 
Jordan, S., \& Kapoor, D. (2016). Re-politicizing participatory action research: Unmasking neoliberalism and the illusions of participation. Educational Action Research, 24(1), 134-149. https://doi.org/10.1080/09650792.2015.1105145

Kemmis, S., McTaggart, R., \& Nixon, R. (2014). The action research planner: Doing critical participatory action research. Singapore: Springer.

McIntyre, L. (2018). Post-truth. Cambridge, MA: MIT Press.

Nichols, T. (2017). The death of expertise: The campaign against established knowledge and why it matters. New York, NY: Oxford University Press.

PRIA Youth Team. (2020). COVID-19 and young people: Impact and solutions. Retrieved from https://www.socialpublishersfoundation.org/knowledge_base/covid-19-andyoung-people-impact-and-solutions/

Riel, M. M. (2017). Action research networks in local and global contexts. In L. L. Rowell, C. D. Bruce, J. M. Shosh, \& M. M. Riel, The Palgrave international handbook of action research (pp. 363-368). Cham: Palgrave Macmillan.

Rönnerman, K., Salo, P., Furu, E. M., Lund, T., Olin, A., \& Jakhelln, R. (2016). Bringing ideals into dialogue with practices: On the principles and practices of the Nordic Network for Action Research. Educational Action Research, 24(1), 46-64. https://doi.org/10.1080/09650792.2015.1069751

Rowell, L., Bruce, C., Shosh, J.M., \& Riel, M. (2017). The Palgrave international handbook of action research. NY: Palgrave Macmillan.

Spooner, M. \& McNinch, J. (Eds.). (2018). Dissident knowledge in higher education. Regina, Saskatchewan: University of Regina Press.

Zuber-Skerritt, O. \& Passfield, R. (2017). Action Learning and Action Research Association (ALARA): History, culture, and sustainability. In L. Rowell, C. D. Bruce, J. M. Shosh, \& M. M. Riel, The Palgrave international handbook of action research (pp. 419-440). Cham: Palgrave Macmillan.

\section{BIOGRAPHICAL NOTE:}

Meagan Call-Cummings is an assistant professor of qualitative methods at George Mason University's School of Education. She writes on critical, participatory, and feminist qualitative methodology, with a specific focus on how validity and ethics are conceptualized. 
Melissa Hauber-Özer is a doctoral candidate in International Education at George Mason University's School of Education. Her research focuses on language and literacy education in migration contexts and employs critical participatory methodology to examine the role of intersectional identities in integration experiences.

Lonnie Rowell is the president of the Social Publishers Foundation and a retired professor at the University of San Diego, where he directed the Counseling Program and the School Counseling emphasis. He is an editor for Educational Action Research and recently coedited a two-part Special Issue on Knowledge Democracy. He is the lead editor of the Palgrave International Handbook of Action Research (2017).

Karen Ross is an assistant professor of conflict resolution at the University of Massachusetts-Boston, where her work focuses on conceptual and methodological issues at the nexus of peace-building, education, and sociopolitical activism. She is also a dialogue practitioner and trainer. 